Int. J. Morphol.,

30(4):1474-1480, 2012

\title{
Head Circumference in Canadian Male Adults: Development of a Normalized Chart
}

\author{
Circunferencia Cefálica en Hombres Adultos Canadienses: Desarrollo de una Tabla Normalizada
}

"A.K.D. Nguyen; ${ }^{*, * *}$ A. A. Simard-Meilleur; C. ${ }^{* *}$ Berthiaume; ${ }^{* * * *, * * *}$ R. Godbout $\&{ }^{*, * *, * * *}$ L. Mottron

NGUYEN, A. K. D.; SIMARD-MEILLEUR, A. A.; BERTHIAUME, C.; GODBOUT, R. \& MOTTRON, L. Head circumference in Canadian male adults: Development of a normalized chart. Int. J. Morphol., 30(4):1474-1480, 2012.

SUMMARY: Macrocephaly has been reported as one of the few physiological markers of several syndromes which are identified during childhood. However, only a limited number of studies have investigated whether macrocephaly persists in adults in these conditions, due to an absence of up-to-date reference charts constructed for typically developing adults. Available adult head circumference reference charts either don't measure individuals beyond 21 years of age, are outdated, mostly use homogeneous samples and most importantly do not account for the individual's height and weight at the same time. Two hundred twenty-one male adults were recruited in a large urban community. For each participant, height, weight and head circumference were measured. A significant positive relationship was found between head circumference and height $(\mathrm{r}=0.379)$ as well as between head circumference and weight $(\mathrm{r}=0.391)$ and a weaker positive correlation with bodymass index $(\mathrm{r}=0.213)$. Charts to determine the level of head circumference abnormalities in adulthood are provided, along with a calculation formula for head circumference based on height and weight. The findings indicate the necessity of taking height and weight into account when measuring head circumference in adults.

KEY WORDS: Head circumference; Reference chart; Height; Weight; Adults.

\section{INTRODUCTION}

Measurement of adult head circumference in neurodevelopmental conditions is relevant for clinical and research purposes. In the case of Autism, adult individuals who were born before the routine application of DSM criteria remain often misdiagnosed or diagnosed under alternative diagnosis. Macrocephaly represents therefore additional information at the time of providing an autism diagnosis in adulthood. More than 15 studies have shown that macrocephaly is one of the few physical signs identified in autism (McCaffery \& Deutsch, 2005). The rate of macrocephaly, defined as a Head Circumference (HC) above the 97 th percentile of a reference population, has been estimated as 15\%-20\% of autistic individuals (Davidovitch et al., 1996; Fombonne et al., 1999; Lainhart et al., 1997; Webb et al., 2007). This finding has some specificity to autism at the group level, as this increase in brain volume and head size is not found in children with other neurodevelopmental conditions such as language disorders (Filipek et al., 1992; Woodhouse et al., 1996), dyslexia (Schultz et al., 1994) and attention deficit with hyperactivity disorder (Castellanos et al., 1994). Macrocephaly defined as $\mathrm{HC}$ above 97th normative percentile may represent only the extreme of a skewing of HC toward high values in the majority of individuals with autism (Fombonne et al.; Lainhart et al.; Miles et al., 2000). However, since most of these studies are performed on infants and preschool children, conclusions (Aylward et al., 2002) regarding the presence of macrocephaly in autistic adults remain limited.

Beside autism, measurement of head circumference is relevant in a multitude of other rare conditions that present with high rates of macrocephaly. 114 syndromes associated with macrocephaly are listed (Winter \& Baraitser, 1996). In some of them, macrocephaly persist into adulthood: Cowden disease, neurofibromatosis type 1, tuberous sclerosis; overgrowth syndromes such as Sotos syndrome (cerebral gigantism), Weaver syndrome, Simpson-Golabi-Behmel syndrome, and macrocephaly-capillary malformation (MCM) syndrome; neuron-cardio-facial-cutaneous syndromes such as Noonan syndrome, Costello syndrome, and cardiofaciocutaneous syndrome and Fragile X syndrome (Williams et al., 2008). 94\% of individuals with a PTEN (a

\footnotetext{
* Département de Psychologie, Université de Montréal, Montréal, Québec, Canada.

** Clinique Spécialisée de l'Autisme, Hôpital Rivières-des-Prairies Montréal, Québec, Canada.

**** Départment de Psychiatrie, Université de Montréal, Montréal, Québec, Canada.
} 
tumor suppressor gene) hamartoma tumor syndrome (such as Cowden syndrome) present with a macrocephaly (Mester et al., 2011). Other syndromes such as neurofibromatosis type 1 (NF1) and tuberous sclerosis (TS) result from a mutation of tumor suppressor genes leading to macrocephalic rates as high as $54 \%$ in NF1 patients (Janeiro et al., 2008), and $9.5 \%$ in TSC patients (Fidler et al., 2008). Both syndromes can have an adulthood age of onset (Roach \& Sparagana, 2004; Ferner et al., 2007), which further emphasizes the need for a valid $\mathrm{HC}$ reference chart for adults.

Despite its need for clinical and research purposes, the use of current adult reference charts for head size is limited by numerous factors. Since head circumference measurements are conducted most often during development, recent head circumference reference charts mainly focus from birth to 16-18 years of age (Aylward et al.; Roche et al., 1987; Nellhaus, 1968). As male subjects' growth usually ends at 21 years of age, pediatric growth charts going from birth to 16-18 years of age are inappropriate to measure young male adult head circumference. Another limit is that the head circumference normative chart most often referenced in adults head circumference studies dates back to almost 20 years and offers only limited information to convert raw scores into standardized values (Bushby et al., 1992). Since mean dimensions of the human body change over generations with changes of nutritional intake and of timing of puberty as possible influencing variables, growth charts need to be updated on a regular basis in any population (Wikland et al., 2002). Another limit in the existing studies is that their participants are recruited in clinical settings, and composed of ethnically or locally homogeneous populations (Roche et al.; Wikland et al.), which limit their validity for North American samples. Finally, and most importantly, available $\mathrm{HC}$ charts did not provide an accurate account of the plausible influence of weight and height on head circumference. The objective of this study was therefore to construct a valid adult head measurement reference chart for typically developing male adults taking into consideration the influence of height and weight variables. Women were not included since it was constructed initially for use with autism spectrum disorders, a condition in which a strong sex ratio in favor of male individuals exists.

\section{SUBJETS AND METHOD}

Subjects. The study was conducted in the area of Montreal (Québec), Canada, an urban community of nearly 3.9 million. 280 male adult subjects were recruited randomly in 4 locations: Hospital personnel, University students, workers at a local factory and YMCA members. This recruiting process allowed the construction of a convenience sample, featuring the diversity within urban North American populations. However, 59 participants were excluded from the initial sample of 280 individuals because of reported personal or family history of psychiatric disorders, including autism, and anxiety/mood disorders yielding a final sample of 221 typically developing subjects. Participation was anonymous and the data collected (age, orbito-frontal head circumference, height, weight, and ethnic origins) used only for the construction of the reference chart. Exclusion criteria included past personal or family history (first and second degree relatives) of neurological conditions, learning disabilities, psychiatric disorders (including autism spectrum disorders) or anxiety/mood disorders.

Procedure. Following a brief explanation of the study, each participant gave verbal consent for their participation. A pretest questionnaire was filled with each participant to assure that they did not meet any of the exclusion criteria. The participants' weight and height were measured by the Life Source Profit Precision digital weighing scale and the Charder HM-200F portable stadiometer respectively. Head circumference was obtained using a non-extensible, flexible measuring tape. Standard landmarks for scalp measurement (Nellhaus; Geraedts et al., 2011) (the nasion, the inion, and above the helix of each ear) were used to measure the head circumference along the horizontal plane: the measuring tape is passed on all four critical reference points.

Statistical Analyses. First, correlations between variables of interest (age, weight, height and head circumference) were investigated. Next, linear regression models predicting head circumference were generated, based on variables significantly correlated with head circumference. Predicted means and estimated variance of residuals were then calculated from the best model, in order to derive head circumference percentiles according to height, weight and the normal probability distribution. Model assumptions of linearity, homoscedacticity and normality were also tested. A cut-off score equivalent to the 97 th or 3 rd percentile was used to determine the presence of macrocephaly or microcephaly respectively. All statistical analyses were performed using SPSS statistical software, version 17.0.

\section{RESULTS}

Model assumptions (linearity, homoscedacticity and normality) were tested and no failure was found. The final sample's age range extended between 18 to 71 years old (mean $=34.72 \pm 13.35$ years). The mean values in the 
reference group were $174.48 \mathrm{~cm}$ in height, $78.52 \mathrm{~kg}$ in weight and $56.69 \mathrm{~cm}$ in head circumference. Table I indicates the participants' ethnicity for a subsample of 137 YMCA participants and factory workers. Although some differences between ethnic groups in height growth curves have been reported (Roche, 1978), growth curve charts produced in non-Caucasian ethnic groups appear relatively comparable to growth standards of Caucasian children, thus not necessitating distinct growth charts for each ethnic group (Nellhaus; Kelly et al., 1997). As a result, ethnic groups were pooled.

Cross-variable correlation analysis yielded a moderate positive correlation between $\mathrm{HC}$ and weight $(\mathrm{r}=$ $0.391 ; \mathrm{p}<0.001)$, and height $(\mathrm{r}=0.379 ; \mathrm{p}<0.001)$, respectively. The correlation between body mass index (BMI) and $\mathrm{HC}(\mathrm{r}=0.213 ; \mathrm{p}=0.001)$ was weaker than the 2 previous correlations while age was not correlated with $\mathrm{HC}(\mathrm{r}=-0.015 ; \mathrm{p}=0.820)$. Hence, weight and height were entered as independent variables within the models yielding three possible regression formulae for predicting head circumference size. Model 1 involved only the influence of height on $\mathrm{HC}$ while Model 2 involved only weight on $\mathrm{HC}$ and Model 3 combined the effects of both variables on HC (Table II).

Regression analyses yielded a significant relationship between weight and head circumference with a coefficient of determination R2 of $0.153(\mathrm{~F}(1,219)=$
39.597; $\mathrm{p}<0.001)$ and a significant relationship between height and head circumference with a coefficient of determination R2 of $0.144(F(1,219)=36.695 ; \mathrm{p}<0.001)$. Combination of both weight and height variables into Model 3 yields the strongest prediction ability with a coefficient of determination R2 of $0.208(\mathrm{~F}(2.218)=28.610 ; \mathrm{p}<$ 0.001 ), and both predictors contributing significantly (weight: $\mathrm{t}(218)=4.210 ; \mathrm{p}<0.001$, height: $\mathrm{t}(218)=3.883$; $\mathrm{p}<0.001)$. Hence, Model 3 was used for the construction of the reference chart. A detailed head circumference chart according to height, weight and the normal probability distribution is presented for the 3rd, 10th, 90th and 97th percentile ranks (Table III).

The current data provides formulas allowing for the estimation of predicted and percentile values of $\mathrm{HC}$ controlling for height and weight:
- PredHC $_{\mathrm{h}, \mathrm{w}}=0.063 *$ height $+0.040 *$ weight +42.618
- $\mathrm{HC}_{\mathrm{h}, \mathrm{w}}(\mathrm{pct})=$ PredHC $_{\mathrm{h}, \mathrm{w}}+1.536 * \mathrm{Z}(\mathrm{pct})$, where $\mathrm{Z}$ is the standard normal value at given percentile.

For example, if a subject is $180 \mathrm{~cm}$ tall and weighs $70 \mathrm{~kg}$, his predicted $\mathrm{HC}$ according to the formula is: $(0.063 * 180)+(0.040 * 70)+42.618=56.76 \mathrm{~cm}$. If the participant's head circumference is $58 \mathrm{~cm}$, which is below the 90th percentile value $(58.73 \mathrm{~cm})$, the subject's HC stands within normal values.

Table I. Ethnic origins of a subsample of subjects in the reference group.

\begin{tabular}{lcc}
\hline Ethnic origins & $\%(\mathbf{n})$ & $\begin{array}{l}\text { \% approx. in Greater Montreal } \\
\text { (Statistics Canada Census 2006) }\end{array}$ \\
\hline European/Caucasian & $73.72(101)$ & 74.49 \\
Arabic & $9.49(13)$ & 6.95 \\
Asian & $5.84(8)$ & 8.72 \\
African & $6.57(9)$ & 7.51 \\
Latin & $4.38(6)$ & 2.33 \\
Participants from J\&J and YMCA & $100(137)$ & \\
\hline
\end{tabular}

Table II. Proposed linear regression models to predict the head circumference size in adults.

\begin{tabular}{lccr}
\hline & Predictors & Regression Formulae & $\boldsymbol{R}^{2}$ \\
\hline Model 1 & Height & $\mathrm{HC}=40.654+(0.092 *$ Height $)$ & 0.144 \\
Model 2 & Weight & $\mathrm{HC}=52.347+(0.055 *$ Weight $)$ & 0.153 \\
Model 3 & Height \& Weight & $\mathrm{HC}=42.618+(0.063 *$ Height $)+(0.040 *$ Weight $)$ & 0.208 \\
\hline
\end{tabular}

$\mathrm{HC}=$ head circumference. 
NGUYEN, A. K. D.; SIMARD-MEILLEUR, A. A.; BERTHIAUME, C.; GODBOUT, R. \& MOTTRON, L. Head circumference in Canadian male adults: Development of a normalized chart. Int. J. Morphol., 30(4):1474-1480, 2012.

Table III. HC predicted percentile values based on regression formulae.

\begin{tabular}{|c|c|c|c|c|c|c|}
\hline Height (cm) & Weight (kg) & Expected HC & Expected HC & Expected HC & Expected HC & Expected HC \\
\hline \multirow[t]{9}{*}{155} & 40 & 51.09 & 52.02 & 53.98 & 55.95 & 56.87 \\
\hline & 50 & 51.49 & 52.42 & 54.38 & 56.35 & 57.27 \\
\hline & 60 & 51.89 & 52.82 & 54.78 & 56.75 & 57.67 \\
\hline & 70 & 52.29 & 53.22 & 55.18 & 57.15 & 58.07 \\
\hline & 80 & 52.69 & 53.62 & 55.58 & 57.55 & 58.47 \\
\hline & 90 & 53.09 & 54.02 & 55.98 & 57.95 & 58.87 \\
\hline & 100 & 53.49 & 54.42 & 56.38 & 58.35 & 59.27 \\
\hline & 110 & 53.89 & 54.82 & 56.78 & 58.75 & 59.67 \\
\hline & 120 & 54.29 & 55.22 & 57.18 & 59.15 & 60.07 \\
\hline \multirow[t]{9}{*}{160} & 40 & 51.41 & 52.33 & 54.30 & 56.27 & 57.19 \\
\hline & 50 & 51.81 & 52.73 & 54.70 & 56.67 & 57.59 \\
\hline & 60 & 52.21 & 53.13 & 55.10 & 57.07 & 57.99 \\
\hline & 70 & 52.61 & 53.53 & 55.50 & 57.47 & 58.39 \\
\hline & 80 & 53.01 & 53.93 & 55.90 & 57.87 & 58.79 \\
\hline & 90 & 53.41 & 54.33 & 56.30 & 58.27 & 59.19 \\
\hline & 100 & 53.81 & 54.73 & 56.70 & 58.67 & 59.59 \\
\hline & 110 & 54.21 & 55.13 & 57.10 & 59.07 & 59.99 \\
\hline & 120 & 54.61 & 55.53 & 57.50 & 59.47 & 60.39 \\
\hline \multirow[t]{9}{*}{165} & 40 & 51.72 & 52.65 & 54.61 & 56.58 & 57.50 \\
\hline & 50 & 52.12 & 53.05 & 55.01 & 56.98 & 57.90 \\
\hline & 60 & 52.52 & 53.45 & 55.41 & 57.38 & 58.30 \\
\hline & 70 & 52.92 & 53.85 & 55.81 & 57.78 & 58.70 \\
\hline & 80 & 53.32 & 54.25 & 56.21 & 58.18 & 59.10 \\
\hline & 90 & 53.72 & 54.65 & 56.61 & 58.58 & 59.50 \\
\hline & 100 & 54.12 & 55.05 & 57.01 & 58.98 & 59.90 \\
\hline & 110 & 54.52 & 55.45 & 57.41 & 59.38 & 60.30 \\
\hline & 120 & 54.92 & 55.85 & 57.81 & 59.78 & 60.70 \\
\hline \multirow[t]{8}{*}{170} & 50 & 52.44 & 53.36 & 55.33 & 57.30 & 58.22 \\
\hline & 60 & 52.84 & 53.76 & 55.73 & 57.70 & 58.62 \\
\hline & 70 & 53.24 & 54.16 & 56.13 & 58.10 & 59.02 \\
\hline & 80 & 53.64 & 54.56 & 56.53 & 58.50 & 59.42 \\
\hline & 90 & 54.04 & 54.96 & 56.93 & 58.90 & 59.82 \\
\hline & 100 & 54.44 & 55.36 & 57.33 & 59.30 & 60.22 \\
\hline & 110 & 54.84 & 55.76 & 57.73 & 59.70 & 60.62 \\
\hline & 120 & 55.24 & 56.16 & 58.13 & 60.10 & 61.02 \\
\hline \multirow[t]{8}{*}{175} & 50 & 52.75 & 53.68 & 55.64 & 57.61 & 58.53 \\
\hline & 60 & 53.15 & 54.08 & 56.04 & 58.01 & 58.93 \\
\hline & 70 & 53.55 & 54.48 & 56.44 & 58.41 & 59.33 \\
\hline & 80 & 53.95 & 54.88 & 56.84 & 58.81 & 59.73 \\
\hline & 90 & 54.35 & 55.28 & 57.24 & 59.21 & 60.13 \\
\hline & 100 & 54.75 & 55.68 & 57.64 & 59.61 & 60.53 \\
\hline & 110 & 55.15 & 56.08 & 58.04 & 60.01 & 60.93 \\
\hline & 120 & 55.55 & 56.48 & 58.44 & 60.41 & 61.33 \\
\hline \multirow[t]{7}{*}{180} & 60 & 53.47 & 54.39 & 56.36 & 58.33 & 59.25 \\
\hline & 70 & 53.87 & 54.79 & 56.76 & 58.73 & 59.65 \\
\hline & 80 & 54.27 & 55.19 & 57.16 & 59.13 & 60.05 \\
\hline & 90 & 54.67 & 55.59 & 57.56 & 59.53 & 60.45 \\
\hline & 100 & 55.07 & 55.99 & 57.96 & 59.93 & 60.85 \\
\hline & 110 & 55.47 & 56.39 & 58.36 & 60.33 & 61.25 \\
\hline & 120 & 55.87 & 56.79 & 58.76 & 60.73 & 61.65 \\
\hline
\end{tabular}




\begin{tabular}{|c|c|c|c|c|c|c|}
\hline \multirow[t]{8}{*}{185} & 60 & 53.78 & 54.71 & 56.67 & 58.64 & 59.56 \\
\hline & 70 & 54.18 & 55.11 & 57.07 & 59.04 & 59.96 \\
\hline & 80 & 54.58 & 55.51 & 57.47 & 59.44 & 60.36 \\
\hline & 90 & 54.98 & 55.91 & 57.87 & 59.84 & 60.76 \\
\hline & 100 & 55.38 & 56.31 & 58.27 & 60.24 & 61.16 \\
\hline & 110 & 55.78 & 56.71 & 58.67 & 60.64 & 61.56 \\
\hline & 120 & 56.18 & 57.11 & 59.07 & 61.04 & 61.96 \\
\hline & 130 & 56.58 & 57.51 & 59.47 & 61.44 & 62.36 \\
\hline \multirow[t]{7}{*}{190} & 70 & 54.50 & 55.42 & 57.39 & 59.36 & 60.28 \\
\hline & 80 & 54.90 & 55.82 & 57.79 & 59.76 & 60.68 \\
\hline & 90 & 55.30 & 56.22 & 58.19 & 60.16 & 61.08 \\
\hline & 100 & 55.70 & 56.62 & 58.59 & 60.56 & 61.48 \\
\hline & 110 & 56.10 & 57.02 & 58.99 & 60.96 & 61.88 \\
\hline & 120 & 56.50 & 57.42 & 59.39 & 61.36 & 62.28 \\
\hline & 130 & 56.90 & 57.82 & 59.79 & 61.76 & 62.68 \\
\hline \multirow[t]{7}{*}{195} & 70 & 54.81 & 55.74 & 57.70 & 59.67 & 60.59 \\
\hline & 80 & 55.21 & 56.14 & 58.10 & 60.07 & 60.99 \\
\hline & 90 & 55.61 & 56.54 & 58.50 & 60.47 & 61.39 \\
\hline & 100 & 56.01 & 56.94 & 58.90 & 60.87 & 61.79 \\
\hline & 110 & 56.41 & 57.34 & 59.30 & 61.27 & 62.19 \\
\hline & 120 & 56.81 & 57.74 & 59.70 & 61.67 & 62.59 \\
\hline & 130 & 57.21 & 58.14 & 60.10 & 62.07 & 62.99 \\
\hline \multirow[t]{7}{*}{200} & 70 & 55.13 & 56.05 & 58.02 & 59.99 & 60.91 \\
\hline & 80 & 55.53 & 56.45 & 58.42 & 60.39 & 61.31 \\
\hline & 90 & 55.93 & 56.85 & 58.82 & 60.79 & 61.71 \\
\hline & 100 & 56.33 & 57.25 & 59.22 & 61.19 & 62.11 \\
\hline & 110 & 56.73 & 57.65 & 59.62 & 61.59 & 62.51 \\
\hline & 120 & 57.13 & 58.05 & 60.02 & 61.99 & 62.91 \\
\hline & 130 & 57.53 & 58.45 & 60.42 & 62.39 & 63.31 \\
\hline
\end{tabular}

$\mathrm{HC}=0.063 *$ height $+0.040 *$ weight +42.618 with estimated standard deviation of residuals of 1.536 .

\section{DISCUSSION}

This study provides an updated head circumference reference chart for a large cohort representative of male adults belonging to an urban Canadian population, taking into account height and weight. Unlike previous studies, this study provides precise measurements about expected head circumference sizes based on a linear regression according to the individual's height and weight on adult subjects.

The current finding highlights the importance of taking into consideration not only height but also weight when calculating standardized measures of head circumference as structural characteristics evolve with age, both during development and adulthood. The correlation between head circumference and weight could be a reflection of bone mass, reflected by height, whereby bone mass of the skull may additionally be influenced by brain size. Accordingly, the cubic value of brain weight is proportional to head circumference even at adulthood (Epstein \& Epstein,
1978). When bone mass is greater, head circumference would be greater, whereas heavier bone mass would be also linked with greater height. The link between weight and head circumference comes therefore from the combination of a heavier brain, adding to the individual's total weight, while adult height remains proportional with head circumference. Whatever is the relative role of these two factors, their combined action predicts $20.8 \%$ of the variation of head circumference. This model is in agreement with the data by Geraedts et al., that recently showed a significant correlation between head circumference and both height and weight in typical children and young adults.

This chart offers a more precise evaluation of macro/ microcephaly than the previous adult reference charts (Roche et al.; Bushby et al.) which did not include the influence of weight. For example, an application of the 
Bushby's standards (Bushby et al.), on the 221 Canadian subjects of this sample would have resulted in a rate of absolute microcephaly at $13.57 \%$, which is discrepant with the normal prevalence (Pilu \& Jeanty, 1999) $(2.5 \%$ at 2 standard deviations and over). Furthermore, the present data updates previously published reference charts (Wikland et al.; Geraedts et al.), as it includes data for subjects beyond the age of 18 years old.

A main limitation to our study is that although the reference group consisted of subjects coming from different backgrounds adding diversity to sample, it is a convenience sample not a true random sample. Also, the data on HC and other variables may be more representative of this region of Canada while it could be less representative in of other parts of the country. Nonetheless, this chart can be used by clinicians and researchers to identify adult patients with micro/macrocephaly, particularly in conditions such as autism, but also multiple rare diseases in which $\mathrm{HC}$ is abnormal in order to investigate the persistence of macrocephaly in adulthood in individuals with those conditions. Whereas the measurement of the head circumference is an integral part of standard pediatric examinations, its assessment might therefore also be aimed at adult subjects on any of the syndromes in question and also on adult relatives of children having such conditions considering the genetic component of those syndromes. Future research should also be extended to female subjects, to study all forms of growth deregulation in the population, including microcephaly. Last, it is important to underline that, if the presence of macro/microcephaly could be an indicator to a particular condition, neurodevelopmental syndromes are defined by a joint presence of multiple features, and the absence of one of this feature may or may not, according to situation, exclude a diagnosis.

Conflict of Interest Statement. The authors declare that they have no conflict of interest.

NGUYEN, A. K. D.; SIMARD-MEILLEUR, A. A.; BERTHIAUME, C.; GODBOUT, R. \& MOTTRON, L. Circunferencia cefálica en hombres adultos canadienses: Desarrollo de una tabla normalizada. Int. J. Morphol., 30(4):1474-1480, 2012.

RESUMEN: La macrocefalia ha sido reportada como uno de los pocos marcadores fisiológicos de varios síndromes que se identifican durante la infancia. Sin embargo, sólo un número limitado de estudios han investigado si la macrocefalia persiste en los adultos con estas condiciones, debido a la ausencia de tablas de referencia actualizadas, construidas para el desarrollo normal de adultos. Las tablas de referencia de circunferencia cefálica disponible para adultos, no miden a los individuos más allá de los 21 años de edad, no están actualizadas, y la mayoría utiliza muestras homogéneas y lo más importante, no toman en cuenta al mismo tiempo la altura y peso del individuo. Fueron reclutados 221 hombres adultos de una comunidad urbana grande. En cada participante se midió la circunferencia cefálica, altura y peso. Se observó una relación significativamente positiva entre la circunferencia cefálica y la altura ( $\mathrm{r}=0,379)$, así como entre la circunferencia cefálica y el peso $(\mathrm{r}=0,391)$, mientras la correlación positiva fue débil con el índice de masa corporal $(\mathrm{r}=$ 0,213). Se proporcionan tablas para determinar el nivel de anormalidades de la circunferencia cefálica en la edad adulta, junto con una fórmula de cálculo para la circunferencia cefálica basada en la altura y el peso. Los resultados indican la necesidad de tomar en cuenta altura y peso al momento de medir la circunferencia cefálica en adultos.

PALABRAS CLAVE: Circunferencia cefálica; Tablas de referencia; Altura; Peso; Adultos.

\section{REFERENCES}

Aylward, E. H.; Minshew, N. J.; Field, K.; Sparks, B. F. \& Singh, $\mathrm{N}$. Effects of age on brain volume and head circumference in autism. Neurology, 59(2):175-83, 2002.

Bushby, K. M.; Cole, T.; Matthews, J. N. \& Goodship, J. A. Centiles for adult head circumference. Arch. Dis. Child., 67(10):1286-7, 1992.

Castellanos, F. X.; Giedd, J. N.; Eckburg, P.; Marsh, W. L.; Vaituzis, A. C.; Kaysen, D.; Hamburger, S. D. \& Rapoport, J. L. Quantitative morphology of the caudate nucleus in attention deficit hyperactivity disorder. Am. J. Psychiatry, 151(12):17916, 1994.

Davidovitch, M.; Patterson, B. \& Gartside, P. Head circumference measurements in children with autism. J. Child Neurol., 11(5):389-93, 1996.
Epstein, H. T. \& Epstein, E. B. The relationship between brain weight and head circumference from birth to age 18 years. Am. J. Phys. Anthropol., 48(4):471-4, 1978.

Ferner, R. E.; Huson, S. M.; Thomas, N.; Moss, C.; Willshaw, H.; Evans, D. G.; Upadhyaya, M.; Towers, R.; Gleeson, M.; Steiger, C. \& Kirby, A. Guidelines for the diagnosis and management of individuals with neurofibromatosis 1. J. Med. Genet., 44(2):81-8, 2007.

Fidler, D. J.; Bailey, J. N. \& Smalley, S. L. Macrocephaly in autism and other pervasive developmental disorders. Dev. Med. Child Neurol., 42(11):737-40, 2000.

Filipek, P.; Richelme, C.; Kennedy, D.; Rademacher, J.; Pitcher, D.; Zidel, S. \& Caviness, V. S. Morphometric analysis of the 
brain in developmental language disorders and autism. Ann. Neurol., 32:475, 1992.

Fombonne, E.; Rogé, B.; Claverie, J.; Courty, S. \& Frémolle, J. Microcephaly and macrocephaly in autism. J. Autism Dev. Disord., 29(2):113-9, 1999.

Geraedts, E. J.; van Dommelen, P.; Caliebe, J.; Visser, R.; Ranke, M. B.; van Buuren, S.; Wit, J. M. \& Oosrdijk, W. Association between head circumference and body size. Horm. Res. Paediatr., 75(3):213-9, 2011.

Janeiro, P. C.; Cunha, M. S.; Cordeiro, I.; Santos, H. G. \& Antunes, N. L. Simultaneous occurrence of neurofibromatosis and tuberous sclerosis, acquired as neo-mutations. Rev. Neurol., 46(6):347-50, 2008

Kelly, A. M.; Shaw, N. J.; Thomas, A. M.; Pynsent, P. B. \& Baker, D. J. Growth of Pakistani children in relation to the 1990 growth standards. Arch. Dis. Child., 77(5):401-5, 1997.

Lainhart, J. E.; Piven, J.; Wzorek, M.; Landa, R.; Santangelo, S. L.; Coon, H. \& Folstein, S. E. Macrocephaly in children and adults in autism. J. Am. Acad. Child Adolesc. Psychiatry, 36(2):282-90, 1997.

McCaffery, P. \& Deutsch, C. K. Macrocephaly and the control of brain growth in autistic disorders. Prog. Neurobiol., 77(1-2):38$56,2005$.

Mester, J. L.; Tilot, A. K.; Rybicki, L. A.; Frazier, T. W. 2nd \& Eng, C. Analysis of prevalence and degree of macrocephaly in patients with germline PTEN mutations and of braun weight in PTEN knick-in murine model. Eur. J. Hum. Genet., 19(7):763-8, 2011.

Miles, J. H.; Hadden, L. L.; Takahashi, T. N. \& Hillman, R. E. Head circumference is an independent clinical finding associated with autism. Am. J. Med. Genet., 95(4):339-50, 2000.

Nellhaus, G. Head circumference from birth to eighteen years: practical composite international and interracial graphs. Pediatrics, 41(1):106-14, 1968.

Pilu, G. \& Jeanty, P. Microcephaly. In: TheFetus.net. 1999. Available in: http://www.sonoworld.com/Client/TheFetus/ page.aspx?id=127\#_edn1

Roach, E. S. \& Sparagana, S. P. Diagnosis of tuberous sclerosis complex. J. Child Neurol., 19(9):643-9, 2004.

Roche, A. F. Growth assessment in abnormal children. Kidney Int., 14(4):369-77, 1978.

Roche, A. F.; Mukherjee, D.; Guo, S. M. \& Moore, W. M. Head circumference data: birth to 18 years. Pediatrics, 79(5):706$12,1987$.
Schultz, R. T.; Cho, N. K.; Staib, L. H.; Kier, L. E.; Fletcher, J. M.; Shaywitz, S. E.; Shankweiler, D. P.; Katz, L.; Gore, J. C.; Duncan, J. S. \& Shaywitz, B. Brain morphology in normal and dyslexic children: the influence of sex and age. Ann. Neurol., 35(6):732-42, 1994.

Webb, S. J.; Nalty, T.; Munson, J.; Brock, C.; Abbott, R. \& Dawson, G. Rate of head circumference growth as a function of autism diagnosis and history of autistic regression. J. Child Neurol., 22(10):1182-90, 2007.

Wikland, K. A.; Luo, Z. C.; Niklasson, A. \& Karlberg, J. Swedish population-based longitudinal reference values from birth to 18 years of age for height, weight and head circumference. Acta Paediatr., 91(7):739-54, 2002.

Williams, C. A.; Dagli, A.; Battaglia, A. Genetic disorders associated with macrocephaly. Am. J. Med. Genet. A, 146A(15):2023-37, 2008.

Winter, R. M. \& Baraitser, M. London dysmorphology database. Oxford, Oxford University Press, 1996.

Woodhouse, W.; Bailey, A.; Rutter, M.; Bolton, P.; Baird, G. \& Le Couteur, A. Head circumference in autism and other pervasive developmental disorders. J. Child Psychol. Psychiatry, 37(6):665-71, 1996.

Correspondence to:

L. Mottron

Clinique Spécialisée des Troubles Envahissants du Développement

Hôpital Rivière-des-Prairies, 7070 Boul

Perras, Montréal (PQ), Canada H1E 1A4

CANADA

Tel :514-323-7260 ext. 2173

Fax :514-328-3533

Email: laurent.mottron@gmail.com

Received: 22-06-2012

Accepted: 07-08-2012 